Check for updates

Cite this: RSC Adv., 2017, 7, 23663

Received 15th March 2017

Accepted 22nd April 2017

DOI: 10.1039/c7ra03078a

rsc.li/rsc-advances

\section{Multifunctional bio carbon: a coir pith waste derived electrode for extensive energy storage device applications $\uparrow$}

\author{
V. Mullaivananathan, P. Packiyalakshmi and N. Kalaiselvi iD *
}

\section{Introduction}

Electrochemical energy storage devices seamlessly occupy the position of sustainable solution offering devices and require immediate attention to combat the alarming threats prevailing against the establishment of greener energy and a cleaner environment, required to be made available for the next generation. Lithium ion batteries (LIBs), sodium ion batteries (SIBs) and supercapacitors (e.g. electrical double layer capacitors) are believed to be potential electrochemical energy storage systems, based on their demonstrated performance in recent years. In lithium ion batteries (LIBs), researchers do pay more attention towards the development of potential electrode materials with a view to improve their electrochemical performance in portable devices and electric vehicles (EV). However, lithium is not abundantly available on the Earth's crust and hence could not offer a cost effective storage solution, especially when large scale energy storage is targeted. As a result, researchers concentrate on the development of sodium-ion batteries (SIBs) as an alternative for LIBs to reduce the cost. ${ }^{1-3}$

Actually, sodium is the fourth most abundant element on the earth and hence provokes renewed interest on the development of eco benign and economically viable sodium-ion technology, wherein sodiation/desodiation facilitating anode requires more

ECPS Division, Central Electrochemical Research Institute, Karaikudi-630006, India. E-mail: kalaiselvicecri@gamil.com; Tel: +91 4565241427

$\dagger$ Electronic supplementary information (ESI) available. See DOI: 10.1039/c7ra03078a attention to make it as a competent SIBs technology with that of LIBs. Despite the similarities found between the chemistry of LIBs and SIBs, diffusion kinetics of is selectively facile due to the larger ionic radius of $\mathrm{Na}^{+}$ion than $\mathrm{Li}^{+}$ion. ${ }^{1}$ For example, graphite that has the interlayer distance of $\sim 0.315 \mathrm{~nm}$, the most commonly used anode material in LIBs, which is not suitable to accommodate more $\mathrm{Na}^{+}$ions in the interlayer spacing, because of its larger ionic radius. In other words, perfect sodiation/ desodiation (shuttling of $\mathrm{Na}^{+}$ion between the electrodes) reaction requires the interlayer distance of nearly $0.37 \mathrm{~nm}^{2}$ In this regard, disordered type of carbonaceous anode materials assume importance, as they are bestowed with the interlayer distance of nearly $0.37 \mathrm{~nm}$, apart from benefits such as low cost, better electrical conductivity, low intercalation potential and environmentally benign nature. SIB technology, otherwise known as the cost effective and energy efficient storage mechanism requires the identification and recommendation of cheap, scalable and facile synthesis driven carbonaceous anodes in order to consider the same as a practically viable technology. As a result, carbonaceous materials derived from biomass waste becomes the choicest anode candidate for SIBs. Despite the adequate numbers of carbon samples derived from biomass such as cellulose, cotton wool, coconut, starch, coffee shells, banana fibers, rice husk, rice straw, algae, cherry stones, pinecone hull and wheat straw are reported as electrodes for use in LIBs, ${ }^{5-15}$ exploration of similar waste-to-wealth driven carbonaceous anodes with comparable or superior electrochemical properties in SIBs assumes vital importance, as one may have a wider choice of selection of anodes based on 
requirement. Recently, $\mathrm{Xu}$ et al., developed dual heteroatom doped carbon derived from shells of broad beans and demonstrated its performance in various electrochemical energy storage devices such as LIBs, SIBs and EDLCs. The obtained capacity from bean derived carbon is $261.5 \mathrm{~mA} \mathrm{~h} \mathrm{~g}^{-1}$ at $1 \mathrm{C}$ rate in LIBs, $\sim 150 \mathrm{~mA} \mathrm{~h} \mathrm{~g}^{-1}$ at $200 \mathrm{~mA} \mathrm{~g}^{-1}$ in SIBs and the specific capacitance is $129 \mathrm{~F} \mathrm{~g}^{-1}$ in EDLCs. The excellent performance is attributed to the presence of dual dopants, viz. nitrogen and sulfur along with the benefits reaped due to the porous structure of carbon. ${ }^{3}$ Similarly, Zhou et al., explored chemically derived carbon from furfuryl alcohol that exhibits a steady state reversible capacity of $115 \mathrm{~mA} \mathrm{~h} \mathrm{~g}^{-1}$ for 1000 cycles at $200 \mathrm{~mA} \mathrm{~g}^{-1}$ current density in SIBs. Herein, the achieved capacity is reported to be due to the spherical structure of carbon, uniform distribution of nanopores and inherently available larger interlayer graphene spacing. ${ }^{4}$ In short, most of the carbon materials derived from biomass exhibit specific capacity in the range of $200-300 \mathrm{~mA} \mathrm{~h} \mathrm{~g}^{-1}$ at a current density of $50 \mathrm{~mA} \mathrm{~g}^{-1}$ in SIBS $^{2,28,36-38}$ and the electrochemical performance of such carbonaceous materials is attributed to advantages such as hetero atom doping, porosity, larger surface area and wider interlayer spacing.

Quite similar to LIBs and SIBs, it is well known that supercapacitor is considered as yet another futuristic electrochemical energy storage device, owing to the high power density and longer cycle life advantages. Among the electrical double layer capacitors (EDLCs) and pseudocapacitors, charges stored in the electrical double layer of EDLCs is due to the electrostatic adsorption of electrolyte ions on the charged electrode interface and in the case of pseudocapacitors, involvement of redox reaction plays a vital role in improving the capacitance behavior. Most commonly, porous carbons are used in EDLCs, owing to their inherent advantages such as low cost, chemical stability, larger surface area, better electronic conductivity and environmentally benign nature. ${ }^{16-18,27,39}$ Carbonaceous materials are capable of exhibiting pseudo-capacitive behavior, especially when pseudo-capacitive effects occur either due to the contribution of nitrogen functional group or due to the presence of micro pores in carbon. ${ }^{\mathbf{1 5 , 1 6 , 1 8 - 2 0 , 4 0 - 4 5}}$ It is noteworthy that microporous carbon delivers superior capacitance than mesoporous carbon and hence receives more importance..$^{17,35}$ Hereagain, various biomass derived carbons are used in EDLCs that include coconut shells, sucrose, corn cob, sugarcane bagasse, banana peel and scrap tires. ${ }^{21-26}$ Hence it is understood that as a sequel to LIBs and SIBs, supercapacitor electrodes also favor hetero atom doping and porous carbon matrix to realize increased conductivity and better transport kinetics respectively.

Towards this direction, our group recently demonstrated the exploration of coir pith derived carbon (CPC) containing no hetero atoms (except oxygen) as an electrode material for LIBs and in Li-S systems, with duly incorporated sulfur in the later case. ${ }^{28,29}$ Intrigued by the current trend to extend the applicability of biomass derived carbons for a wide range of energy storage applications, we intented to explore the possibility of deploying CPC in SIBs and supercapacitors, which is the motivation behind this work. Accordingly, we have prepared CPC800, CPC-850 and CPC-900 samples by heat treating CPC to the mentioned temperatures individually and investigated for its suitability in SIB and EDLC cell assembly. Interestingly, CPC850 qualifies itself as a better performing electrode, compared with those of 800 and $900{ }^{\circ} \mathrm{C}$ treated derivatives. The study substantiates the multifunctional capability of CPC with a progressive capacity of $220 \mathrm{~mA} \mathrm{~h} \mathrm{~g}^{-1}$ in SIBs for 300 cycles and about $191 \mathrm{~F} \mathrm{~g}^{-1}$ in supercapacitors for 10000 cycles.

\section{Experimental section}

\subsection{Synthesis procedure of CPC}

Details related to the preparation of coir pith derived carbon and the results of physicochemical characterization of CPC are discussed in one of our earlier reports. ${ }^{29}$ Precisely, coir pith waste collected from the industry was washed repeatedly with water followed by ethanol rinsing and dried at $80{ }^{\circ} \mathrm{C}$. Subsequently, pre-carbonisation at $350{ }^{\circ} \mathrm{C}$ and $\mathrm{KOH}$ activation with respect to temperatures such as 800,850 and $900{ }^{\circ} \mathrm{C}$ were carried out. The resultant black powder was washed with $1 \mathrm{M}$ $\mathrm{HCl}$ and triple distilled water to attain neutral $\mathrm{pH}$ and dried further at $80{ }^{\circ} \mathrm{C}$ in vacuum to obtain CPC-800, CPC-850 and CPC-900 individually.

\subsection{Electrode fabrication}

The electrodes were prepared from a combination of $70 \mathrm{wt} \%$ active material with $20 \mathrm{wt} \%$ super $\mathrm{P}$ carbon and $10 \mathrm{wt} \%$ polyvinylidene difluoride (PVdF) binder. The PVdF binder was dissolved in $\mathrm{N}$-methylpyrrolidone and a mixture containing premixed active material and super $\mathrm{P}$ carbon was added to the solution to get a homogenous slurry. The slurry was coated on a $\mathrm{Cu}$ foil (current collector), dried under vacuum at $80{ }^{\circ} \mathrm{C}$ for $12 \mathrm{~h}$ and pressed with 3 ton pressure. Such a hot roll pressed electrode was cut in to circular shape $(14 \mathrm{~mm})$ and the electrodes typically had an active material content of 2-3 $\mathrm{mg}$. The electrode was further dried under vacuum at $80{ }^{\circ} \mathrm{C}$ for $2 \mathrm{~h}$, prior to the assembling of cells in an argon-filled glove box and hermetically sealed after cell fabrication using crimp sealing machine. Electrochemical characterization was carried out with freshly fabricated 2032 coin cells consisting of CPC vs. $\mathrm{Na}^{+} / \mathrm{Na}$

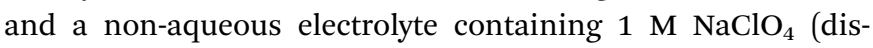
solved in $1: 1 \mathrm{v} / \mathrm{v}$ EC : PC) along with polypropylene separator. In EDLCs, $80 \mathrm{wt} \%$ active material, $10 \mathrm{wt} \%$ super $\mathrm{P}$ carbon and $10 \mathrm{wt} \%$ PVdF were mixed to obtain a slurry with $N$-methylpyrrolidone. The slurry was coated on nickel foam using Doctor's blade method and the electrodes (CPC//CPC) were used to fabricate EDLC assembly along with $6 \mathrm{M} \mathrm{KOH}$ electrolyte.

\subsection{Electrochemical characterization}

Electrochemical characterization such as cyclic voltammetry (CV), electrochemical impedance spectroscopy (EIS) and galvanostatic charge/discharge studies were performed to analyse the symmetric behavior of CPC electrode in alkaline medium (6 M $\mathrm{KOH})$ and in the potential range between 0 and $1.0 \mathrm{~V}$. The gravimetric capacitance $\left(\mathrm{F} \mathrm{g}^{-1}\right)$ has been evaluated from the charge/discharge studies for a single electrode by using the formula, 


$$
C=2 \times \frac{(I \Delta t)}{m \Delta V}
$$

where, $C=$ capacitance (in $\mathrm{F} \mathrm{g}^{-1}$ ), $I=$ applied current $\left(\right.$ in $\mathrm{Ag}^{-1}$ ), $\Delta t=$ discharge time (in seconds), $m=$ mass of active loaded material (in gram) and $\Delta V=$ difference between the voltage range (in voltage).

The energy density $E\left(\mathrm{~W} \mathrm{~h} \mathrm{~kg}^{-1}\right)$ of the electrodes was calculated by,

$$
E\left(\mathrm{~W} \mathrm{~h} \mathrm{~kg}{ }^{-1}\right)=\frac{1}{2} C \Delta V^{2}=\frac{1000 \times C \times \Delta V^{2}}{2 \times 4 \times 3600}=\frac{C \times \Delta V^{2}}{28.8}
$$

where, $C$ is the gravimetric capacitance of the electrode $\left(\mathrm{F} \mathrm{g}^{-1}\right)$ and $\Delta V$ is the width of the voltage window $(\mathrm{V})$.

\section{Results and discussion}

Since the physical characterization of CPC and its suitability for LIB applications have been elaborated elsewhere ${ }^{29}$ the present communication is restricted to the discussion on the electrochemical behavior of CPC anode in SIBs and in supercapacitor applications, with a view to recommend the same as a carbon with multifunctional electrode properties, applicable to a wide variety of energy storage devices.

\subsection{Electrochemical behavior of CPC anode in SIBs}

Electrochemical performance of CPC anodes viz., CPC-800, CPC850 and CPC-900 was evaluated individually using the configuration consisting of CPC anode against sodium metal. Quite similar to its behavior in LIBs, CPC-850 exhibits superior performance as anode in SIBs and as a potential electrode in EDLC assembly, which could be understood as the effect of synthesis and processing protocol that plays a vital role in fine-tuning the physical properties to best suit with the requirements of electrochemically better performing storage device applications. In other words, synthesis-structure-property related electrochemical advantages favor CPC-850 electrode for its multifunctional suitability and superseding performance characteristics in electrochemical energy storage device applications.

Fig. 1a exhibits the cyclic voltammogram of CPC-850 anode, recorded at $0.05 \mathrm{mV} \mathrm{s}^{-1}$ in the potential range of $0.01-3.0 \mathrm{~V}$ region. Presence of sharp peak at $0.2 \mathrm{~V}$ (Fig. 1a) corresponds to the decomposition of the electrolyte and the formation of SEI on the surface of the anode during initial cycling process. Subsequently, the peak due to SEI disappears (from second cycle onwards) and the presence of characteristic peak pair, corresponding to the intercalation and de-intercalation of sodium ions within the interlayer spacing of CPC could be seen around $0 \mathrm{~V}^{30,31,38}$ However, the peak intensity of the reduction peak decreases upon progressive cycling, which is an indication of probable fade in capacity that becomes unavoidable to some extent, especially upon extended cycles. Albeit, the reversible behavior of $\mathrm{CV}$ peaks is found to get sustained, which is in favor of the maintenance of stable SEI at the surface of the anode that facilitates smooth and facile diffusion path for sodiation and desodiation between the electrodes. Hence, the stability of currently investigated CPC-850 electrode and its capability to
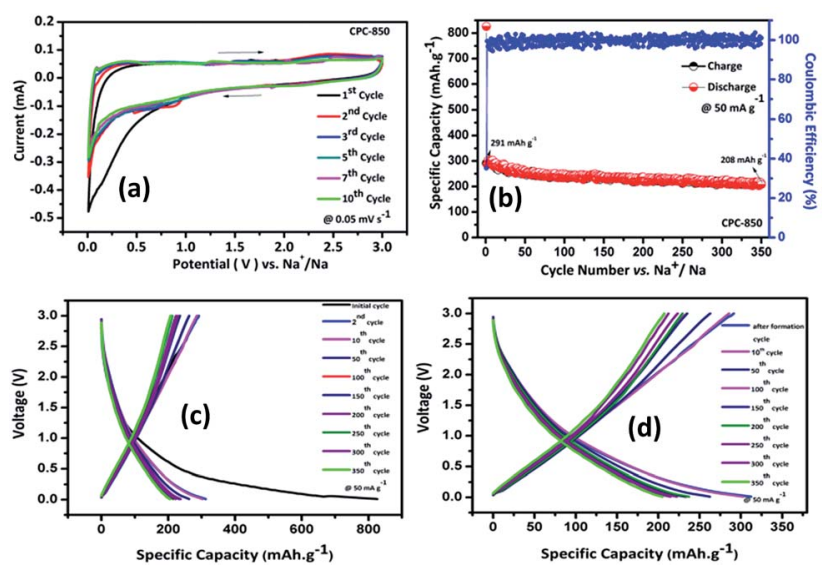

Fig. 1 (a) Cyclic voltammogram of CPC-850 anode vs. sodium metal recorded at a scan rate $0.05 \mathrm{mV} \mathrm{s}^{-1}$ (b) charge-discharge behavior of CPC-850 anode in SIBs at $50 \mathrm{~mA} \mathrm{~g}^{-1}$, (c) voltage vs. Capacity profile containing initial formation cycle (d) capacity vs. voltage behavior of CPC anode upon progressive cycles after formation cycle.

exhibit nominal and reversible capacity behavior in SIB assembly could be understood from CV studies. Similar and characteristic behavior of CPC anode has been observed with CPC-800 and CPC-900 anodes also (Fig. S1a and b广), which is quite interesting.

Results obtained from the charge-discharge studies of CPC850 anode performed by keeping sodium metal as the counter and reference electrode are furnished in Fig. 1b-d. Fig. 1b displays the variation of capacity as a function of cycle number, wherein an initial capacity of $826 \mathrm{~mA} \mathrm{~h} \mathrm{~g}^{-1}$ is exhibited by CPC850 anode, when cycled@50 $\mathrm{mA} \mathrm{g}^{-1}$ condition. However the corresponding charge capacity is $291 \mathrm{~mA} \mathrm{~h} \mathrm{~g}^{-1}$, leading to a coulombic efficiency of $35 \%$. Further, the second cycle discharge capacity is $288 \mathrm{~mA} \mathrm{~h} \mathrm{~g}^{-1}$, corresponding to an irreversible capacity loss of $65 \%$. Such a high and initial irreversible capacity value is not unusual and is due to the formation of SEI and the decomposition of electrolyte associated with the initial cycling process. However, the (declined) capacity of $288 \mathrm{~mA} \mathrm{~h}$ $\mathrm{g}^{-1}$ observed during the second cycle is found to get maintained upon progressive cycling due to the stabilization of SEI and the advantageous anode characteristics of CPC chosen for the study i.e., a steady state capacity of around $280 \mathrm{~mA} \mathrm{~h} \mathrm{~g}^{-1}$ is observed for about 20 initial cycles. After 20 cycles, the capacity gradually decreases and we observe progressive reversible capacity in the range of $220-240 \mathrm{~mA} \mathrm{~h} \mathrm{~g} \mathrm{~g}^{-1}$ for 300 cycles, which is quite interesting. Herein, the coulombic efficiency has increased from 35 to $>95 \%$, especially upon extended cycles viz., up to 300 cycles, which is yet another encouraging behavior. This in turn is an indication that the formed SEI gains stability to facilitate favorable transport kinetics across the interface, thereby substantiating the $\mathrm{CV}$ results comparable with those of any other storage mechanism. From Table S3, $\dagger$ one can clearly understand the variation and maintenance of capacity values obtained from CPC-850 anode cycled at $50 \mathrm{~mA} \mathrm{~g}{ }^{-1}$ current condition with an interval of every 25 cycles up to 300 cycles. More interestingly, the currently obtained capacity and 
coulombic efficiency are comparable with other biomass derived carbon anodes, reported elsewhere. ${ }^{36,46}$ Further, we cycled the half cells of corresponding CPC-800 and CPC-900 anodes individually at $50 \mathrm{~mA} \mathrm{~g}^{-1}$ current density for comparison purpose and the results are shown in Fig. S1. $\dagger$ As provided in Table 1, and from Fig $\mathrm{S} 1, \uparrow$ it is evident that discharge capacity values of 797 and $769 \mathrm{~mA} \mathrm{~h} \mathrm{~g}^{-1}$, corresponding to the charge capacity values of 243 and $228 \mathrm{~mA} \mathrm{~h} \mathrm{~g}^{-1}$ are obtained with respect to CPC-800 and CPC-900 anodes leading to an irreversible capacity loss of about 64 and $67 \%$ respectively. In the subsequent cycles, CPC-800 and CPC-900 anodes maintain a nominal capacity value of $210 \mathrm{~mA} \mathrm{~h} \mathrm{~g}^{-1}$ up to 50 cycles. On the other hand, CPC-850 anode exhibits $260 \mathrm{~mA} \mathrm{~h} \mathrm{~g}^{-1}$ for 50 cycles, thus indicating the superiority of the same over other CPC anodes in SIB applications also. Based on the fact that, we have already demonstrated the superior performance of CPC-850 anode in LIBs with reasonable rate capability behavior, the present study renders value addition to CPC, with a special relevance to CPC-850 for its multifunctional capabilities in storage device assembly. ${ }^{29}$ In addition, CPC-850 exhibits superior electrochemical performance upon extended cycles also, when compared with other reported carbons, which is evident from Table S3. $\dagger$ Fig. 1c and d correspond to the voltage $v s$. capacity behavior of CPC anode with and without the formation cycle, from which one can clearly understand that CPC-850 anode exhibits better maintenance of $220-240 \mathrm{~mA} \mathrm{~h} \mathrm{~g}{ }^{-1}$ of capacity during 3-300 cycles. Plateau found in the $0.4-0.2 \mathrm{~V}$ region (Fig. 1c) coincides with that of the $\mathrm{CV}$ peak position. Similarly, the extraction of capacity due to the intercalation and de-intercalation of sodium ions below $0.2 \mathrm{~V}$ region is also justified from the current observation. ${ }^{32,33}$ Hence, the possibility of tapping a steady state progressive capacity along with an acceptable coulombic efficiency behavior of CPC anode within the select potential range of $0.01-3.0 \mathrm{~V}$ has been demonstrated. Further, upon cycling at $1000 \mathrm{~mA} \mathrm{~g}^{-1}$ condition, CPC-850 anode delivers a nominal discharge capacity of $\sim 134 \mathrm{~mA} \mathrm{~h} \mathrm{~g}^{-1}$ with a coulombic efficiency 95\% (after formation cycle) and a steady state reversible capacity of $\sim 114 \mathrm{~mA} \mathrm{~h} \mathrm{~g}^{-1}$ is observed efficiency $\sim 99 \%$ upto 1000 cycles, which is in favor of its suitability as a high rate anode. There is no deviation in the voltage profile exhibited by CPC anode@1000 $\mathrm{mA} \mathrm{g}^{-1}$ condition, when compared with its behavior at $50 \mathrm{~mA} \mathrm{~g}^{-1}$ current density (Fig. 2a and $b$ ), thus enumerating its versatile stability for extended
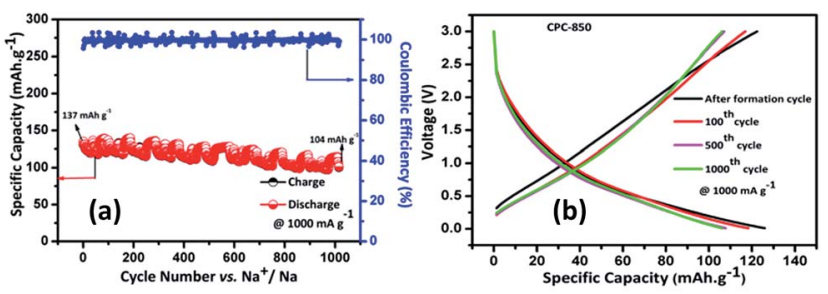

Fig. 2 (a) Charge-discharge behavior of CPC anode at $1000 \mathrm{~mA} \mathrm{~g}^{-1}$, (b) voltage vs. Capacity behavior CPC-850 anode upon progressive cycles after formation cycle.

application at high rate conditions. In addition, Table $\mathrm{S} 4 \dagger$ depicts the details of capacity obtained from CPC-850 anode at $1000 \mathrm{~mA} \mathrm{~g}^{-1}$ current condition for every 100 cycles upto 1000 cycles, from which one can understand that CPC-850 anode is capable of exhibiting nearly $95 \%$ capacity retention upto 1000 cycles. Such an observation is yet another supporting factor that provides ample scope to conclude that CPC-850 anode is capable of providing tolerance in terms of cycling and structural stability upon progressive cycles with respect to moderate and high current density conditions. Subsequently, CPC-850 anode was subjected to various high current density conditions and examined for its rate capability behavior. In other words, CPC anode was investigated under current densities such as 0.05 , $0.1,0.25,0.5,0.75,1,1.25,1.5,1.75,2,3$ and $5 \mathrm{~A} \mathrm{~g}^{-1}$, corresponding to $0.13,0.26,0.67,1.34,2.01,2.68,3.36,4.03,4.7,5.37$, 8.06 and $13.44 \mathrm{C}$ rates (based on the theoretical capacity of 372 $\mathrm{mA} \mathrm{h} \mathrm{g}{ }^{-1}$ for graphite in LIBs) on a continuous mode of chargedischarge process by allowing the cell to experience each current density individually for select number of cycles. Nominal capacity values of $350,288,240,201,174,156,145$, $129,118,110,87$ and $54 \mathrm{~mA} \mathrm{~h} \mathrm{~g}{ }^{-1}$ are obtained with the increasing current density condition, varying between 0.05 and $5 \mathrm{~A} \mathrm{~g}^{-1}$ range. Here again, a nominal capacity of $\sim 50 \mathrm{~mA} \mathrm{~h} \mathrm{~g}^{-1}$ has been observed@13.44C (corresponding to $5 \mathrm{~A} \mathrm{~g}^{-1}$ ) current density, which is quite encouraging. Hence, the suitability of CPC-850 anode for SIBs in line with the reported behavior of other biomass derived carbons ${ }^{1-4}$ has been demonstrated through the present study (Fig. 3).

With a view to understand the role of internal resistance and interface kinetics on the electrochemical behavior of CPC-850

Table 1 Cycling performance of CPC-850 anode upon extended cycles at $50 \mathrm{~mA} \mathrm{~g}^{-1}$ current density condition in SIBS

\begin{tabular}{|c|c|c|c|c|c|c|}
\hline Cycle no. & \multicolumn{2}{|l|}{ CPC-800 } & \multicolumn{2}{|l|}{ CPC-850 } & \multicolumn{2}{|l|}{ СPC-900 } \\
\hline 1 & 243 & 797 & 291 & 826 & 228 & 769 \\
\hline 2 & 247 & 279 & 286 & 288 & 220 & 251 \\
\hline 10 & 229 & 236 & 280 & 280 & 244 & 231 \\
\hline 40 & 207 & 215 & 266 & 272 & 201 & 201 \\
\hline 50 & 200 & 207 & 260 & 261 & 212 & 204 \\
\hline
\end{tabular}



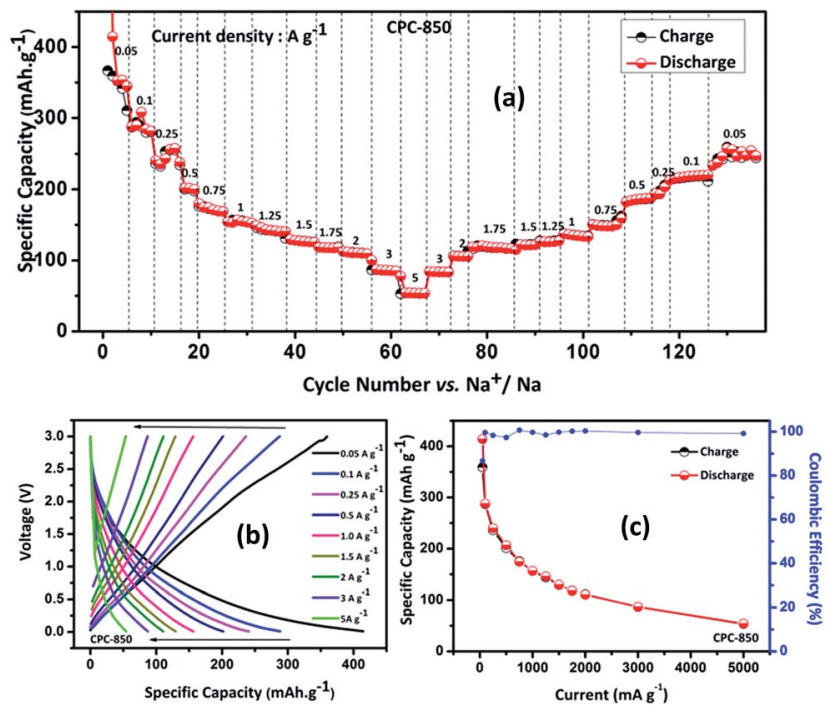

Fig. 3 (a) Rate capability behavior of CPC-850 anode at various current rates with respect to sodium metal (b) voltage vs. Capacity behavior of CPC-850 anode for corresponding rate capability studies (c) capacity obtained from CPC-850 anode at various current densities vs. $\mathrm{Na}^{+} / \mathrm{Na}$.

anode (selected as a typical example) upon extended cycles, we performed A.C. impedance analysis and the results are displayed in Fig. 4. The impedance analysis was done in the 100 $\mathrm{kHz}$ to $10 \mathrm{mHz}$ frequency range and the Nyquist plot obtained for the cell before and after cycling is furnished in Fig. 4. The recorded impedance spectrum of the as fabricated cell consists of two semicircles at low and high frequency region. Among the two, the semicircle at high frequency region is due to the decomposition of electrolyte and the formation of SEI layer, which in turn initiates and further facilitates the sodiation and desodiation process. Similarly, the low frequency semicircle could be correlated to the resistance between the electrode surface and electrolyte, otherwise represented as $R_{\mathrm{ct}}$ and the value is observed to be around $1700 \Omega$. Such a high internal resistance value is the characteristic behavior of microporous carbon, as understood from literature..$^{34}$ On the other hand, impedance of the cell recorded after cycling contains one

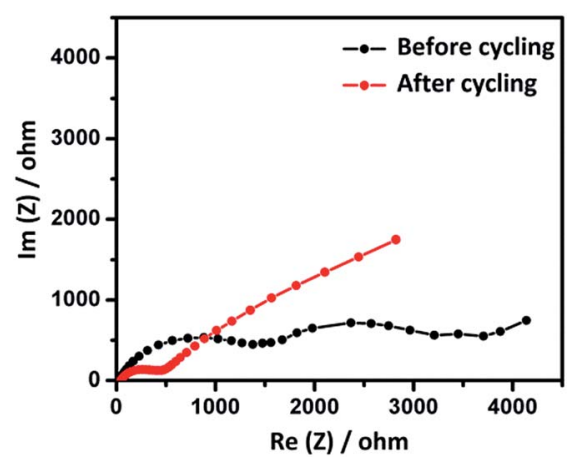

Fig. 4 Impedance behavior of CPC-850 anode recorded in the frequency region $100 \mathrm{kHz}$ to $10 \mathrm{mHz}$ measured vs. $\mathrm{Na}^{+} / \mathrm{Na}$. semicircle and the charge transfer resistance $R_{\mathrm{ct}}$ is found to be around $500 \Omega$, which is a significantly reduced value, obtained due to the extended cycling of the cell under investigation. Such a reduced internal resistance behavior is in favor of the formation and existence of stable SEI, desirable for better sodiation and desodiation related transport kinetics, facilitated mainly through the interface driven diffusion property. Hence, the possibility of realizing extended steady state capacity behavior upon successive cycles could be understood.

Based on the encouraging electrochemical performance exhibited by CPC anode in SIBs, attempt to explore the same for supercapacitor application has been made and the results obtained are described below.

\subsection{Electrochemical performance of CPC electrode in supercapacitor}

Intrigued by the larger surface area holding microporous carbon content and the presence of graphene sheet like morphology, attempt was made to investigate CPC anode with a surface area of $2500 \mathrm{~m}^{2} \mathrm{~g}^{-1}$ along with the presence of micropores for its suitability in supercapacitor applications.

The capacitance behavior of CPC electrodes has been measured by cyclic voltammetry and galvanostatic chargedischarge studies. Herein, symmetric capacitance of CPC electrodes was tested by using $6 \mathrm{M} \mathrm{KOH}$ aqueous electrolyte. Fig. 5a-c shows the CV curves obtained with different scan rates such as 5, 10, 100 and $300 \mathrm{mV} \mathrm{s}^{-1}$, applied individually to the symmetric (CPC//CPC) CPC-800, CPC-850 and CPC-900 cells in the potential range of 0 to $1 \mathrm{~V}$. Appearance of more or less rectangular shaped $\mathrm{CV}$ curves correspond to the capacitance behavior of CPC electrode, which in turn could be attributed to the possible reaction taking place between the electrolyte and the surface of carbon. Further, one can observe an increasing intensity behavior with the increasing scan rate by retaining the rectangular curves, which in turn evidences the ability of CPC electrodes to perform at high current density conditions also. Upon comparison, it is evident that CPC-800 and CPC-900 electrodes are not successful in maintaining the rectangular shaped CV curve and in exhibiting linearly increasing peak
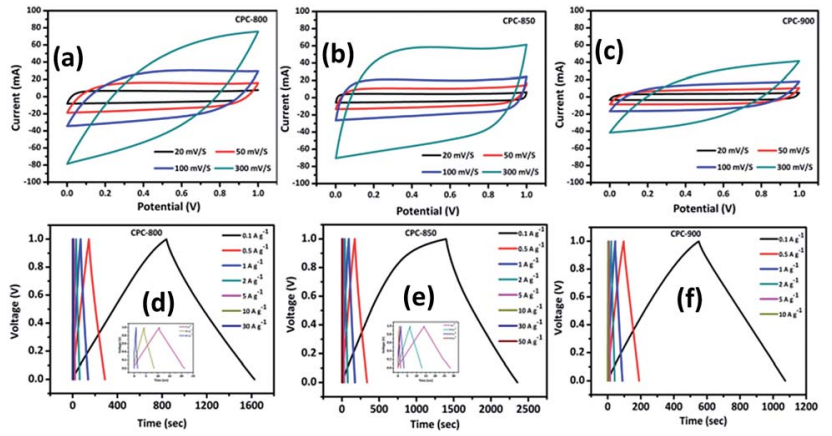

Fig. $5(\mathrm{a}-\mathrm{c})$ Cyclic voltammogram of CPC//CPC supercapacitor recorded at various scan rates in $6 \mathrm{M} \mathrm{KOH}$ electrolyte for corresponding CPC-800, CPC-850, CPC-900 electrodes and (d-f) shows the charge discharge characteristics of CPC anodes at various current condition in presence of $6 \mathrm{M} \mathrm{KOH}$ electrolyte. 
current values as a function of increasing scan rate (Fig. 5b and c). Typically, comparison of CV behavior at $300 \mathrm{mV} \mathrm{s}^{-1}$ (Fig. S2 $\dagger$ ) condition clearly evidences the superiority of CPC-850 over other two electrodes viz., CPC-800 and CPC-900 deployed in EDLC assembly. Galvanostatic charge-discharge behavior of CPC based symmetric capacitors exhibits triangular shaped curves, as appended in Fig. $5 \mathrm{~d}-\mathrm{f}$, which is an indication of double layer capacitive behaviour. ${ }^{48-51}$ Variation of voltage and time as a function of varying current density is shown in Fig. 5d-f, which is in line with the expected and reported behaviour. ${ }^{48-50}$

Subsequently, rate capability performance of $\mathrm{CPC} / / \mathrm{CPC}$ (CPC-800, CPC-850 and CPC-900) assembly has been examined using current densities such as $0.1,0.25,0.5,0.75,1.0,2.0$, $5.0,10,30$ and $50 \mathrm{~A} \mathrm{~g}^{-1}$, wherein appreciable capacitance values of $191,173,170,169,168,152,150,128,102$ and $70 \mathrm{~F} \mathrm{~g}^{-1}$ have been obtained respectively from CPC-850 (Fig. 6a). In addition, Table 2 shows the comparison of capacitance obtained from CPC-800 and CPC-900 electrodes based EDLC assembly along with CPC-850 based symmetric capacitor at various current densities. Among the chosen CPC samples, CPC-850 exhibits superior performance than other electrodes (Table 2). In particular, when subjected to current densities of 1, 2, 5 and 10 $\mathrm{A} \mathrm{g}^{-1}$, CPC-850//CPC-850 exhibits a symmetric capacitance of $170,152,150$ and $128 \mathrm{~F} \mathrm{~g} \mathrm{~g}^{-1}$ initially and the capacitance behavior is found to be reversible even after 10000 cycles (Fig. 7a). This is an indication that the CPC-850//CPC-850 arrangement withstands higher current density along with the capability of delivering acceptable capacitance values upon prolonged cycles also. The cycling stability of CPC-850 symmetric cell shown in Fig. $7 \mathrm{~b}$ at various current densities $\left(1,2,5\right.$ and $\left.10 \mathrm{~A} \mathrm{~g}^{-1}\right)$ also evidences the unaffected triangular curve that gets retained with the original shape even after 10000 cycles and irrespective of the current density condition. Further, CPC-850//CPC-850 exhibits about $102 \mathrm{~F} \mathrm{~g}^{-1}$ up to 10000 cycles, when investigated under the influence of $30 \mathrm{~A} \mathrm{~g}^{-1}$ current density. Hence, it is understood that when one moves from a current density value of 1 to $50 \mathrm{~A} \mathrm{~g}^{-1}$, appreciable capacitance value with a fairly acceptable loss of capacitance is observed with the currently studied CPC-850//CPC-850 system, which is the highlight of the study. Similarly, the capacitance retention calculated as a function of current density viz. 1, 2, 5
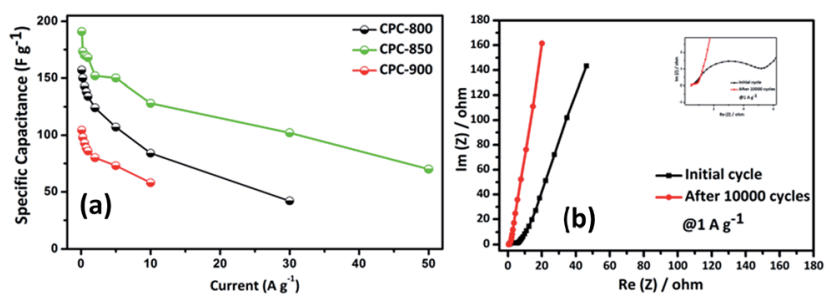

Fig. 6 (a) Specific capacitance of CPC-800, CPC-850 and CPC-900 symmetric capacitor in $6 \mathrm{M} \mathrm{KOH}$ electrolyte at different current densities (b) impedance spectrum corresponds to before and after cycled CPC-850 symmetric cell@1 $\mathrm{A} \mathrm{g}^{-1}$ recorded in the frequency region $100 \mathrm{kHz}$ to $10 \mathrm{mHz}$.
Table 2 EDLC behavior of CPC//CPC symmetric cells at various current density conditions in $6 \mathrm{M} \mathrm{KOH}$ electrolyte

\begin{tabular}{llll}
\hline \multirow{2}{*}{$\begin{array}{l}\text { Current density } \\
\left(\mathrm{A} \mathrm{g}^{-1}\right)\end{array}$} & \multicolumn{3}{l}{ Capacitance $\left(\mathrm{in} \mathrm{F}^{-1}\right)$} \\
\cline { 2 - 4 } 0.1 & CPC-800 & CPC-850 & CPC-900 \\
\hline 0.25 & 157 & 191 & 104 \\
0.5 & 150 & 173 & 98 \\
0.75 & 143 & 170 & 93 \\
1 & 138 & 169 & 88 \\
2 & 134 & 168 & 86 \\
5 & 124 & 152 & 80 \\
10 & 107 & 150 & 73 \\
30 & 84 & 128 & 58 \\
50 & 42 & 102 & - \\
\hline
\end{tabular}
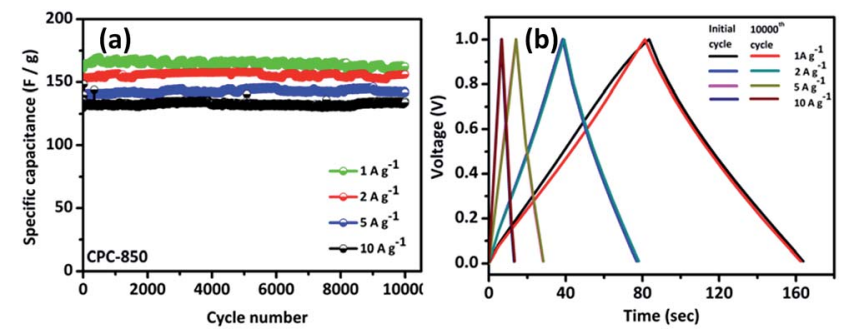

Fig. 7 (a) Charge-discharge studies of CPC-850//CPC-850 symmetric capacitor at 1, 2, 5 and $10 \mathrm{~A} \mathrm{~g}^{-1}$ in $6 \mathrm{M} \mathrm{KOH}$ electrolyte for 10000 cycles (b) cycling stability of CPC-850//CPC-850 initial and after 10000 cycles.

and $10 \mathrm{~A} \mathrm{~g}^{-1}$ condition up to 10000 cycles has been furnished in Fig. S3. $\dagger$ Interestingly, the retention behavior reaches the value of $\sim 99 \%$ and gets maintained up to 10000 cycles, irrespective of the current density being deployed, viz. 1,2, 5 or $10 \mathrm{~A}$ $\mathrm{g}^{-1}$ with a special relevance to CPC-850 electrode (Fig. S3†). The obtained capacitance values from symmetric CPC-850 cell in presence of $6 \mathrm{M} \mathrm{KOH}$ electrolyte is superior than other bioderived carbon materials, as found in Table S4. $\dagger$ Based on these observations, it is stated that the currently deployed CPC anode finds its suitability for supercapacitor applications under versatile cycling conditions.

Energy density calculated for CPC-850 electrode from the symmetric cell falls in the order of 6.6, 6.0, 5.9, 5.3, 5.2, 4.4, 3.5 and $2.4 \mathrm{~W} \mathrm{~h} \mathrm{~kg}^{-1}$ corresponding to $0.1,0.25,0.5,1,2,5,10,30$ and $50 \mathrm{~A} \mathrm{~g}^{-1}$ current rates, which is higher than other CPC electrodes, as understood from Fig. S4. $\dagger$ The obtained energy density values are comparable with those of lignin derived carbon $\left(5.8 \mathrm{~W} \mathrm{~h} \mathrm{~kg}^{-1}\right),{ }^{50}$ bamboo based biomass derived activated carbon $\left(2.0 \mathrm{~W} \mathrm{~h} \mathrm{~kg}^{-1}\right)^{51}$ and rice husk derived carbon (5.11 $\left.\mathrm{W} \mathrm{h} \mathrm{kg}{ }^{-1}\right) .^{52}$ Based on these grounds, the current study recommends that CPC-850 could be considered as the most suitable electrode for supercapacitor applications.

Fig. 6b shows the impedance spectrum of CPC-850//CPC-850 in presence of $6 \mathrm{M} \mathrm{KOH}$ electrolyte solution, which describes the kinetic behavior of initial and post cycling behavior of CPC850//CPC-850 cell at $1 \mathrm{~A} \mathrm{~g}^{-1}$ current condition recorded in the 
frequency range of $100 \mathrm{kHz}$ to $10 \mathrm{mHz}$ at $10 \mathrm{mV}$ amplitude. The obtained spectrum is identical with those obtained from other activated carbons. ${ }^{46}$ The calculated $R_{\mathrm{ct}}$ values of CPC-850 symmetric cell is $4.3 \Omega$ for the initial cycle and the same is found to get reduced to the extent of $0.5 \Omega$ after cycled at $1 \mathrm{~A} \mathrm{~g}^{-1}$ current condition. Similarly, with respect to solution resistance, a gradual decrease of internal resistance $\left(R_{\mathrm{s}}\right)$ from 0.67 to $0.48 \Omega$ is observed. Herein, absence of significant variation of resistance with respect to the electrode surface after 10000 cycles, as evident from the Nyquist plot substantiates the excellent stability of the CPC-850 electrodes towards electrolyte solution. ${ }^{47}$ From the current study, CPC-850 is recommended as yet another potential electrode for EDLC applications.

\section{Conclusions}

In summary, we conclude that $\mathrm{CPC}-850$ is found to be a suitable electrode material compared with those of CPC-800 and CPC900 for sodium-ion battery and EDLC applications. In sodiumion batteries, CPC-850 delivers an appreciable capacity of 220 $\mathrm{mA} \mathrm{h} \mathrm{g}{ }^{-1}$ upto 300 cycles and withstands high current rates such as $1 \mathrm{~A} \mathrm{~g}^{-1}$ with an acceptable capacity value of $\sim 110 \mathrm{~mA} \mathrm{~h}$ $\mathrm{g}^{-1}$ for 1000 cycles. Further, rate capability study endorses its suitability upto $13.44 \mathrm{C}$ rate $\left(5 \mathrm{~A} \mathrm{~g}^{-1}\right)$ condition, which is quite remarkable. In the case of EDLCs studies, CPC-850 performs predominant capacitance behavior over other CPC electrodes in such a manner that it delivers appreciable specific capacitance values of 168,152 and $150 \mathrm{~F} \mathrm{~g} \mathrm{~g}^{-1}$ at 1,2 and $5 \mathrm{~A} \mathrm{~g}^{-1}$ current density conditions and the observed capacitance is found to be stable up to 10000 cycles. Interestingly, at a current density $10 \mathrm{~A}$ $\mathrm{g}^{-1}$, CPC-850 symmetric cell exhibits the acceptable capacitance of $128 \mathrm{~F} \mathrm{~g}^{-1}$ and the cell tolerates $50 \mathrm{~A} \mathrm{~g}^{-1}$ condition also. The encouraging electrochemical performance of CPC-850 in electrochemical energy storage devices could be endorsed to the presence of micropores, larger surface area and the graphene sheet like structure of CPC. In short, the study demonstrates the multifunctional capability of CPC-850 as a suitable electrode material for a wide variety of electrochemical energy storage devices such as SIBs and EDLCs, apart from its proven performance in LIBs and Li-S systems.

\section{Acknowledgements}

CSIR, New Delhi and DST, New Delhi are greatly acknowledged for financial support through MULTIFUN and GAP-14/16 projects respectively.

\section{References}

1 C. Yuliang, X. Lifen, L. S. Maria, W. Wei, S. Birgit, X. Jie, Z. Nie, V. S. Laxmikant, Y. Zhengguo and L. Jun, Nano Lett., 2012, 12, 3783-3787.

2 S. Fei, Z. Hongli, L. Wei, W. Jiayu, Z. Lihui, D. Jiaqi, Z. Bin, H. Xiaogang, F. Kun and H. Liangbing, ACS Appl. Mater. Interfaces, 2015, 7, 23291-23296.
3 X. Guiyin, H. Jinpeng, D. Bing, N. Ping, P. Jin, D. Hui, L. Hongsen and Z. Xiaogang, Green Chem., 2015, 17, 16681674.

4 Z. Dehua, P. Maryam, Y. Zhenzhen, G. P. Vilas, D. K. Fulya, J. Jacob, C. F. Henry and S. J. Christopher, J. Mater. Chem. A, 2016, 4, 6271-6275.

5 V. Palomares, P. Serras, I. Villaluenga, K. B. Hueso, J. Carretero-Gonźalez and T. Rojo, Energy Environ. Sci., 2012, 5, 5884-5901.

6 E. Peled, V. Eshkenazi, Y. Rosenberg, P. Emanuel, E. Victor and R. Yuri, J. Power Sources, 1998, 76, 153-158.

7 S. H. Guo, J. H. Peng, W. Li, K. B. Yang, L. B. Zhang, S. M. Zhang and H. Y. Xia, Appl. Surf. Sci., 2009, 255, 84438449.

8 Y. J. Hwang, S. K. Jeong, K. S. Nahm, J. S. Shin and A. M. Stephan, J. Phys. Chem. Solids, 2007, 68, 182-188.

9 A. M. Stephan, T. P. Kumar, R. Ramesh, S. Thomas, A. K. Jeong and K. S. Nahm, J. Mater. Sci. Eng. A, 2006, 430, 132-137.

10 L. Wang, Z. Schnepp and M. M. Titirici, J. Mater. Chem. A, 2013, 1, 5269-5273.

11 F. Zhang, K. X. Wang, G. D. Li and J. S. Chen, Electrochem. Commun., 2009, 11, 130-133.

12 X. L. Wu, L. L. Chen, S. Xin, Y. G. Guo, Q. S. Kong and Y. Z. Xia, ChemSusChem, 2010, 3, 703-707.

13 J. C. Arrebola, A. Caballero, L. Hernán, J. Morales, M. Olivares-Marín and V. Gómez-Serrano, J. Electrochem. Soc., 2010, 157, A791-A797.

14 L. Chen, Y. Z. Zhang, C. H. Lin and D. Xiao, J. Mater. Chem. A, 2014, 2, 9684-9690.

15 E. Frackowiak, Phys. Chem. Chem. Phys., 2007, 9, 1774-1785.

16 A. G. Pandolfo and A. F. Hollenkamp, J. Power Sources, 2006, 157, 11-27.

17 F. Beguin, V. Presser, A. Balducci and E. Frackowiak, Adv. Mater., 2014, 26, 2283.

18 G. A. Ferrero, A. B. Fuertes and M. Sevilla, J. Mater. Chem. A, 2015, 3, 2914-2923.

19 C. O. Ania, V. Khomenko, E. Raymundo-Pinero, J. B. Parra and F. Beguin, Adv. Funct. Mater., 2007, 17, 1828-1836.

20 F. Ma, H. Zhao, L. Sun, Q. Li, L. Huo, T. Xia, S. Gao, G. Pang, Z. Shi and S. Feng, J. Mater. Chem., 2012, 22, 13464-13468.

21 L. Sun, C. Tian, M. Li, X. Meng, L. Wang, R. Wang, J. Yin and H. Fu, J. Mater. Chem. A, 2013, 1, 6462-6470.

22 L. Wei and G. Yushin, Carbon, 2011, 49, 4830-4838.

23 M. Genovese, J. H. Jiang, K. Lian and N. Holm, J. Mater. Chem. A, 2015, 3, 2903-2913.

24 P. Hao, Z. H. Zhao, J. Tian, H. D. Li, Y. H. Sang, G. W. Yu, H. Q. Cai, H. Liu, C. P. Wong and A. Umar, Nanoscale, 2014, 6, 12120-12129.

25 Y. K. Lv, L. H. Gan, M. X. Liu, W. Xiong, Z. J. Xu, D. Z. Zhu and D. S. Wright, J. Power Sources, 2012, 209, 152-157.

26 M. J. Zhi, F. Yang, F. K. Meng, M. Q. Li, A. Manivannan and N. Q. Wu, ACS Sustainable Chem. Eng., 2014, 2, 1592-1598.

27 W. Jiacheng and K. Stefan, J. Mater. Chem., 2012, 22, 2371023725.

28 K. Balakumar, R. Sathish and N. Kalaiselvi, Electrochim. Acta, 2016, 209, 171-182. 
29 V. Mullaivananathan, R. Sathish and N. Kalaiselvi, Coir Pith Derived Bio-carbon: Demonstration of Potential Anode Behavior in Lithium-ion Batteries, Electrochim. Acta, 2017, 225, 143-150.

30 K. Tang, R. J. White, X. K. Mu, M. M. Titirici, P. A. van Aken and J. Maier, ChemSusChem, 2012, 5, 400-403.

31 W. Heng-guo, W. Zhong, M. Fan-lu, M. De-long, H. Xiao-lei, W. Li-min and Z. Xin-bo, ChemSusChem, 2013, 6, 56-60.

32 D. Jia, W. Huanlei, L. Zhi, K. Alireza, C. Kai, X. Zhanwei, Z. Beniamin, T. Xuehai, M. L. Elmira, C. O. Brian and M. David, ACS Nano, 2013, 7, 11004-11015.

33 K. R. Saravanan, V. Mullaivananathan and N. Kalaiselvi, Electrochim. Acta, 2015, 176, 670-678.

34 Y. Xia and R. Mokaya, Adv. Mater., 2004, 16, 1553-1558.

35 Z. Wu, W. Li, Y. Xia, P. Webley and D. Zhao, J. Mater. Chem., 2012, 22, 8835-8845.

36 M. M. Titirici, R. J. White, N. Brun, V. L. Budarin, D. S. Su, F. D. Monte, J. H. Clark and M. J. MacLachlan, Chem. Soc. Rev., 2015, 44, 250-290.

37 Z. Wang, L. Qie, L. Yuan, W. Zhang, X. Hu and Y. Huang, Carbon, 2013, 55, 328-334.

38 H. G. Wang, Z. Wu, F. L. Meng, D. L. Ma, X. L. Huang, L. M. Wang and X. B. Zhang, ChemSusChem, 2013, 6, 56-60.

39 L. Qie, W. M. Chen, Z. H. Wang, Q. G. Shao, X. Li, L. X. Yuan, X. L. Hu, W. X. Zhang and Y. H. Huang, Adv. Mater., 2012, 24, 2047-2050.

40 F. Su, C. K. Poh, J. S. Chen, G. Xu, D. Wang, Q. Li, J. Lin and X. W. Lou, Energy Environ. Sci., 2011, 4, 717-724.

41 L. F. Chen, X. D. Zhang, H. W. Liang, M. G. Kong, Q. F. Guan, P. Chen, Z. Y. Wu and S. H. Yu, ACS Nano, 2012, 6, 70927102 .
42 Z. S. Wu, S. B. Yang, Y. Sun, K. Parvez, X. L. Feng and K. Mullen, J. Am. Chem. Soc., 2012, 134, 9082-9085.

43 Y. Mao, H. Duan, B. Xu, L. Zhang, Y. S. Hu, C. C. Zhao, Z. X. Wang, L. Q. Chen and Y. S. Yang, Energy Environ. Sci., 2012, 5, 7950-7955.

44 D. Zhang, Y. Hao, L. Zheng, Y. Ma, H. Feng and H. Luob, J. Mater. Chem. A, 2013, 1, 7584-7591.

45 W. Yu, H. Wang, S. Liu, N. Mao, X. Liu, J. Shi, W. Liu, S. Chen and X. Wang, J. Mater. Chem. A, 2016, 4, 5973-5983.

46 Y. X. Xu, Z. Y. Lin, X. Zhong, X. Q. Huang, N. O. Weiss, Y. Huang and X. F. Duan, Nat. Commun., 2014, 5, 4554.

47 J. Yuting, Y. Jun, W. Xiaoliang, S. Dandan, Z. Qihang, J. Lili, Y. Deren and F. Zhuangjun, J. Power Sources, 2016, 307, 190198.

48 M. Lu, Z. Yu, H. Yating, H. H. Kuan, K. Qingqing, L. Huajun, H. Zhigang, Z. Dan and W. John, RSC Adv., 2015, 5, 93079313.

49 Y. Kun, K. Ling-Bin, S. Kui-Wen, D. Yan-Hua, S. Ming, H. Bing, L. Yong-Chun and K. Long, Appl. Surf. Sci., 2016, 364, 850-861.

50 D. Saha, Y. Li, Z. Bi, J. Chen, J. K. Keum, D. K. Hensley, H. A. Grappe, H. M. Meyer, S. Dai, M. P. Paranthaman and A. K. Naskar, Langmuir, 2014, 30, 900-910.

51 C. S. Yang, Y. S. Jang and H. K. Jeong, Bamboo-based activated carbon for supercapacitor applications, Curr. Appl. Phys, 2014, 14, 1616-1620.

52 Y. Ellie, T. Lih, M. Lingeswarran, N. Eng-Poh, A. Farook, M. Abdul Rahman, J. Rajan and C. Kwok Feng, Electrochim. Acta, 2016, 192, 110-119. 